\title{
Rancang Bangun Prototype Robot Pengantar Barang Cargo Berbasis Arduino Mega dengan IoT
}

\author{
Suyatmo $^{1}$, Catra Indra cahyadi ${ }^{2}$, Syafriwel $^{3}$, Rizaldy Khair ${ }^{4, *}$, Iswandi Idris ${ }^{4}$ \\ ${ }^{1}$ Teknologi Pemeliharaan Pesawat Udara, Politeknik Penerbangan Medan, Indonesia \\ ${ }^{2}$ Teknik Listrik Bandar Udara, Politeknik Penerbangan Medan, Indonesia \\ ${ }^{3}$ Teknik telekomunikasi dan navigasi udara, Politeknik Penerbangan Medan, Indonesia \\ ${ }^{4}$ Teknologi Komputer, Politeknik LP3I Medan, Indonesia \\ Email: ${ }^{2}$ catraindracahyadi@gmail.com, ${ }^{3}$ syafriwel.lp3i@gmail.com, ${ }^{4, *}$ rizaldyk.lp3i@gmail.com, ${ }^{5}$ iswandi.idris@ $@$ plm.ac.id \\ Email Penulis Koresponden: rizaldyk.lp3i@gmail.com
}

\begin{abstract}
Abstrak-Cargo merupakan muatan barang yang diangkut dengan menggunakan kapal laut, pesawat udara, atau alat angkutan lainnya. Berdasarkan penjelasan tersebut dengan kata lain cargo terbagi dari tiga jenis angkutan yaitu, udara, darat, dan laut. Layanan khusus angkutan barang yang menggunakan pesawat udara angkutan khusus barang disebut juga sebagai cargo service. Service ini bisa diselenggarakan oleh suatu perusahaan penerbangan regular yang melayani penumpang, tetapi dapat pula oleh suatu perusahaan penerbangan khusus angkutan barang. Dengan perkembangan teknologi otomasi pada industri sangat dibutuhkan robot untuk membantu memenuhi kebutuhannya dengan cepat. Dengan ini dikembangkan teknologi robotika untuk membantu meringankan pekerjaan manusia di masa depan. Robot pengantar barang adalah robot yang diciptakan untuk membantu pekerjaan dalam pengantaran barang ke dalam cargo pesawat. Robot ini dapat barang secara otomatis. Robot pengatar barang ini menggunakan metode Internet Of Things yang sudah terhubung dengan pengendali jarak jauh smartphone berbasis aplikasi android. Penulisan kode program menggunakan Arduino IDE 1.8.9 serta menggunakan Android sebagai pengontrolan robot. Robot ini menggunakan 4 channel line tracker sensor, 2 buah motor DC dan driver motor sebagai pengendali, Arduino uno sebagai otak pada system robot ini. Hasil dari penelitian ini menghasilkan prototype robot yang dapat mengantarkan barang kedalam cargo pesawat yang ada di bandar udara.
\end{abstract}

Kata Kunci: Arduino Mega, Cargo, Android Studio, Line Follower, Internet Of Things

\begin{abstract}
Cargo is the goods transported by ship, aircraft or other types of transportation. Cargo is divided into three types of transportation, namely, air, land and sea. Cargo service is a special service for transporting goods using aircraft. This service can be organized by a regular airline that serves passengers, but can also be carried out by a specialized airline freight company. With the development of industrial automation technology, robots are needed to help meet their needs quickly. With this developed robotics technology to help alleviate human work in the future. Goods delivery robot is a robot created to help work in delivering goods to aircraft cargo. This robot can stuff automatically. This goods transfer robot uses the Internet of Things method that is already connected to a smartphone remote control based on an android application. Writing program code using Arduino IDE 1.8.9 and using Android as a robot control. This robot uses 4 channel line tracker sensors, 2 DC motors and motor drivers as controllers, Arduino uno as the brain in this robot system. The results of this study produce a prototype robot that can deliver goods into aircraft cargo in airports.
\end{abstract}

Keywords: Arduino Mega, Cargo, Android Studio, Line Follower, Internet Of Things

\section{PENDAHULUAN}

Semakin majunya sistem komunikasi dan teknologi informasi pada masa sekarang ini, berdampak pada perubahan banyak sistem, salah satunya sistem pengiriman barang. Jasa pengiriman barang memang memiliki peranan penting terhadap pertumbuhan ekonomi, khususnya pada angkutan barang yang menggunakan pesawat udara. Transportasi yang semakin baik dan berkembang cepat serta ditunjang dengan adanya kemajuan ilmu pengetahuan dan teknologi. Dalam dunia industri, teknologi robotika telah diimplementasikan pada mesin-mesin industri. Teknologi robotika dipilih karena beberapa keunggulan diantaranya yaitu cepat, teliti, mampu bekerja secara full time dan otomatis. Peran robot sekarang ini umumnya digunakan sebagai maninan bagi kalangan ekonomi atas, namun dibidang industri, peran robot lebih dari itu. Robot industri dapat melakukan pekerjaan yang membutuhkan presisi dan akurasi tingi, bahkan pada pekerjaan berskala sangat kecil dimana mata manusia tak dapat lagi melihatnya, misalnya dalam proses manufaktur IC.

Saat ini teknologi elektronika semakin berkembang pesat, khususnya teknologi yang berhubungan dengan pengontrol otomatis, sehingga manusia selalu mencari proses otomatisasi yang pengoperasiannya dapat digunakan dengan mudah. Salah satu teknologi elektronika otomatisasi yang berkembang saat ini adalah bidang robotika. Robotika bukanlah sesuatu yang baru saat ini, sehingga pengembangan dari robot ini sudah banyak dilakukan dalam segala hal pengaplikasiannya. Dimana hampir disemua kalangan meminati dan juga menggunakannya. Salah satunya adalah robot pengantar barang. Pada penelitian ini peneliti akan mengaplikasikan robot pengantar yang bergerak pada jalur khusus, dan dikendalikan untuk membawa serta menaruh barang pada lokasi pengambilan hingga tujuan pengantaran barang oleh pengendali. Pada umumnya robot line follower hanya berjalan pada garis warna hitam dan lantai warna putih atau sebaliknya namun jika diterapkan pada mesin pengantar barang tentu harus lebih adaptif terhadap perubahan warna lantai pada jalur landasan pada bandar udara. Berdasarkan pembahasan di atas, maka dari itu dibuatlah Prototype Robot Pengantar Barang Cargo Berbasis Arduino Mega dengan IoT (Internet Of Things). Tujuan dari penelitian ini 
adalah untuk merancang dan mengimplementaikan sistem robot pengantar barang yang dikendalikan oleh smartphone berbasis android.

\section{METODE PENELITIAN}

\subsection{Blok Diagram}

Perancangan sistem Line follower terdiri dari beberapa blok sistem (Gambar 1) yang terintegrasi menjadi satu sistem. Pembagian blok sistem dibagi menjadi blok user input dan sensor, blok pengolahan data, dan blok keluaran.

Berikut adalah diagram blok dari sistem yang digunakan:

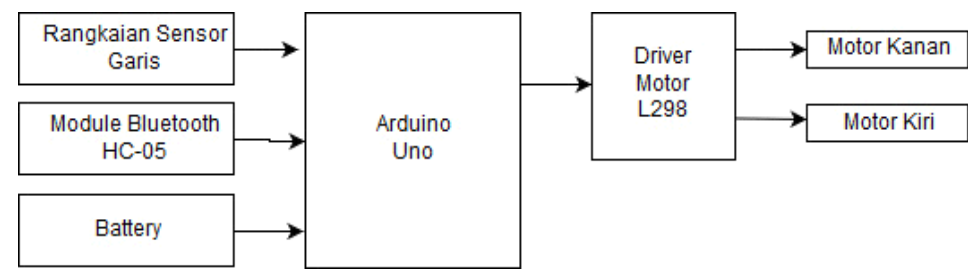

Gambar 1. Blok diagram sistem

Penjelasan dan fungsi dari masing-masing blok adalah sebagai berikut:

a) Arduino Uno berfungsi sebagai pusat kendali dari sistem kerja rangkaian sebagai kontrol rangkaian keseluruhan.

b) Modul Bluetooth HC-05 berfungsi untuk koneksi antar Arduino dengan Android.

c) Battery yang digunanakan berupa baterai 9v sebagai sumber tegangan semua rangkaian elektronika.

d) Sensor garis berfungsi untuk membaca jalur berwarna hitam menuju ke ruangan.

e) Driver motor L298 yang berfungsi sebagai pengendali motor kanan dan motor kiri.

\subsection{Flowchart}

Skema kerja sistem secara keseluruhan dapat dilihat pada gambar 2 dan desain alat pada gambar 3.

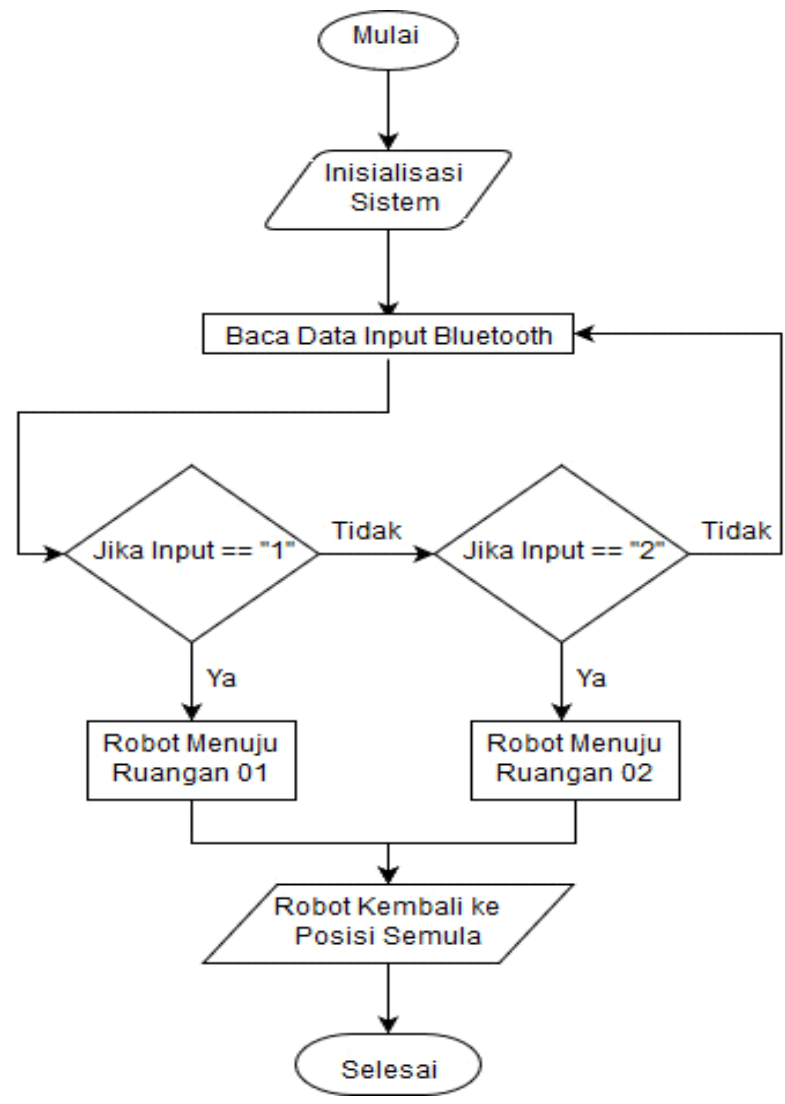

Gambar 2. Flowchart 


\section{HASIL DAN PEMBAHASAN}

Gambar berikut merupakan rancangan dari alat bangun prototype robot pengantar barang cargo berbasis arduino mega dengan iot

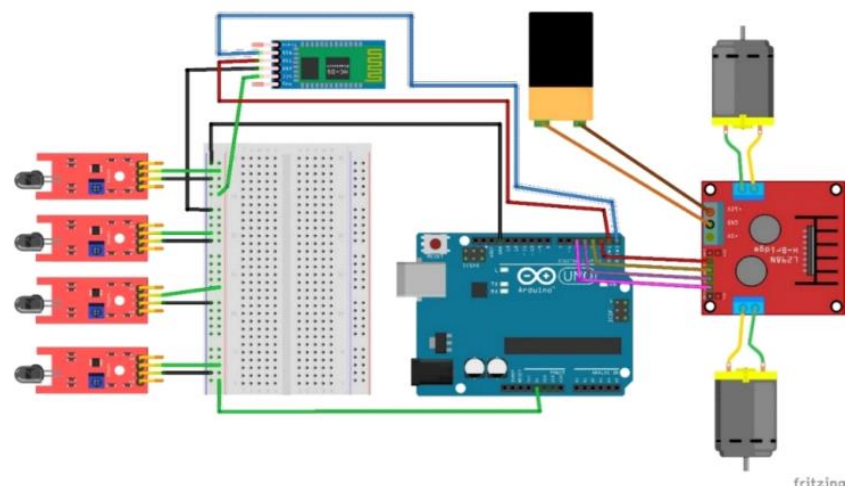

Gambar 3. Desain Alat

Bagian utama dari alat tersebut adalah mikrokontroler, yang di gunakan peneliti adalah Arduino unoR3 (Gambar 4) yang berfungsi menyambungkan alat ke komputer menggunakan kabel usb printer, dan bahasa pemograman Arduino merupakan pemograman bahasa $\mathrm{C}$ yang sudah disederhanakan syntax bahasa pemogramannya sehinga mempermudan kita dalam mempelajari mikrokontroler.

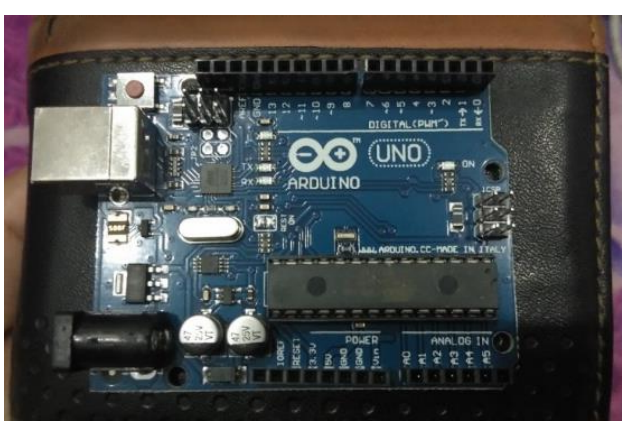

Gambar 4. Arduino Uno R3

Peneliti menggunakan driver motor (Gambar 5) berguna untuk mengendalikan motor servo.

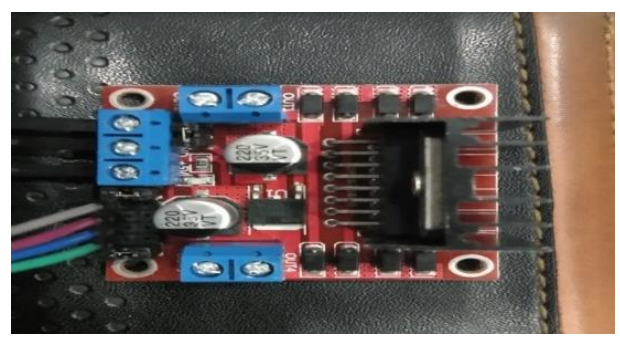

Gambar 5. Driver Motor

Motor Servo (Gambar 6) digunakan peneliti untuk mengerakkan roda agar tetap berjalan dengan mulus.

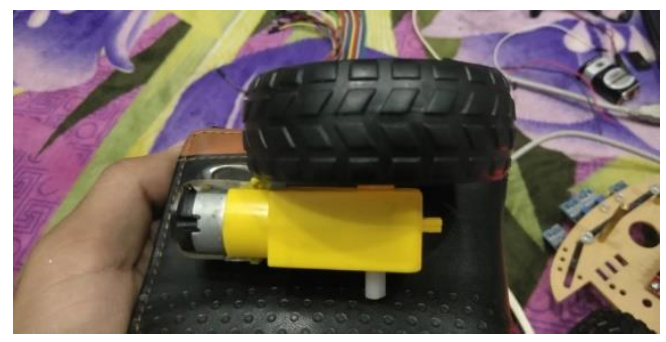

Gambar 6. Motor servo 
Peneliti menggunakan Line Follower casing (Gambar 7) adalah untuk mempermudah perakitan line follower, agar peletakan perakitan alat tidak beantakan.

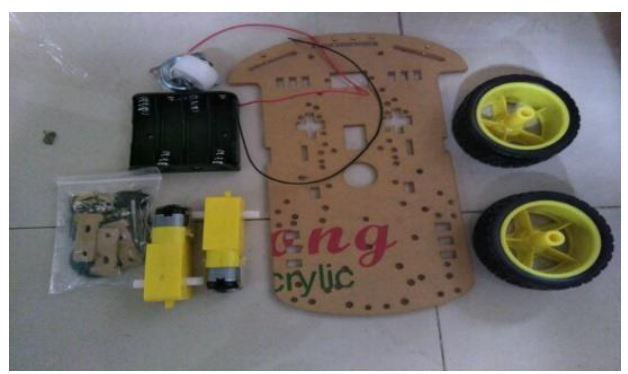

Gambar 7. Line Follower Casing

Robot Line Follower merupakan jenis robot beroda yang bergerak berdasarkan jalur garis (Line) yang sudah ditentukan dengan daya menggerak berupa motor. Robot pengikut garis (Line Follower) yang memungkinkan manusia lebih mudah mengangkat barang atau memindahakn barang ketempat lain dalam bidang industri serta dapat juga digunakan sebagai alat transportasi otomatis. Robot Line Follower adalah suatu jenis Robot yang pergerakannya dengan mendeteksi garis sehingga Robot terseut dapat melakukan perpindahan posisi dari satu titik ke titik yang lain.

Sensor Fotodiaoda (Gambar 8) berfungsi untuk membaca jalur ysg telah di buat oleh peneliti. Sensor LED dan Photodioda adalah sensor untuk mendeteksi ada atau tidaknya suatu obyek. Dalam dunia robotika, sensor LED dan Photodioda seringkali digunakan untuk mendeteksi ada atau tidaknya suatu garis pembimbing gerak robot atau lebih dikenal dengan istilah "Line Follower Robot " atau " Line Tracer Robot". Prinsip kerja Sensor LED dan Photodioda adalah memanfaatkan sifat cahaya yang akan dipantulkan jika mengenai benda berwarna terang dan akan diserap jika mengenai benda berwarna gelap. Sebagai sumber cahaya kita gunakan LED (Light Emiting Diode) yang akan memancarkan cahaya merah. Dan untuk menangkap pantulan cahaya LED, kita gunakan photodioda. Jika sensor berada diatas garis hitam maka photodioda akan menerima sedikit sekali cahaya pantulan. Tetapi jika sensor berada diatas garis putih maka photodioda akan menerima banyak cahaya pantulan. Sensor Ultrasonik (Gambar 9) digunakan agar bisa mengindari halangan atau rintang di dalam lintasan. Sensor ultrasonik dipasang pada bagian depan robot, sehingga terlihat mata dari robot. Sensor ini akan mengukur jarak dari objek-objek yang ada disekelilingnya. Jika jarak yang dideteksi adalah sangat dekat, maka dapat disimpulkan bahwa terdapat objek yang sangat dekat dengan sensor. Sehingga robot harus menghindari dengan cara berbelok ataupun bermanuver kearah yang lainnya.

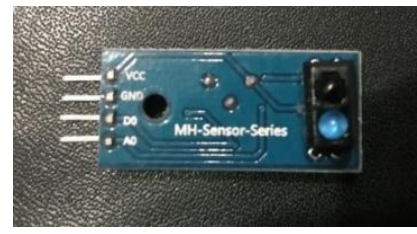

Gambar 8. Sensor Fotodioda

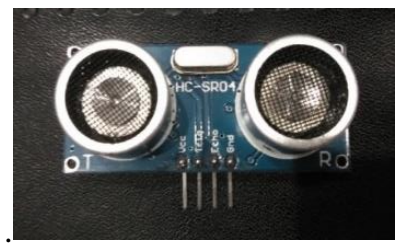

Gambar 9. Sensor Ultrasonic

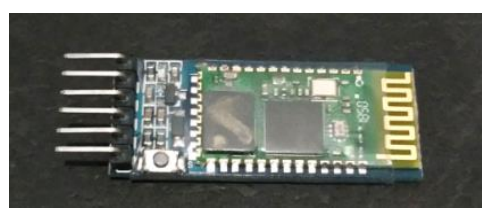

Gambar 10. Module Bluetooth

Module Bluetooth (Gambar 10) digunakan peneliti ini berfungsi untuk mengkoneksikan ke android sebagai kontrol penentu tujuan. Keunggulan Bluetooth antara lain robustness (ketehanan yang baik, seperti terhadap interferensi), perangkat yang tidak kompleks, daya yang rendah dan biaya murah. Bluetooth beroperasi 
di pita frekuensi 2,4 GHz yang merupakan puta unlicensed ISM (Industrial, Scientific, and medical) dengan standar IEEE (Intsitute of Elektrical and Electronics Engineers) 802.11B.

\subsection{Pengujian Alat}

Pengujian alat dilakukan dengan cara membuat jalur menggunakan silotip hitam, jalankan robot untuk membaca jalur dalam menentukan tujuan. Setelah jalur terdata maka gunakan kontrol android untuk menentukan kemana robot akan pergi.

\subsection{Pengkodean Program}

Pengcodingan (Gambar 11) di lakukan menggunakan software Arduino, apa saja yang telat tersaji di lihat dari gambar.

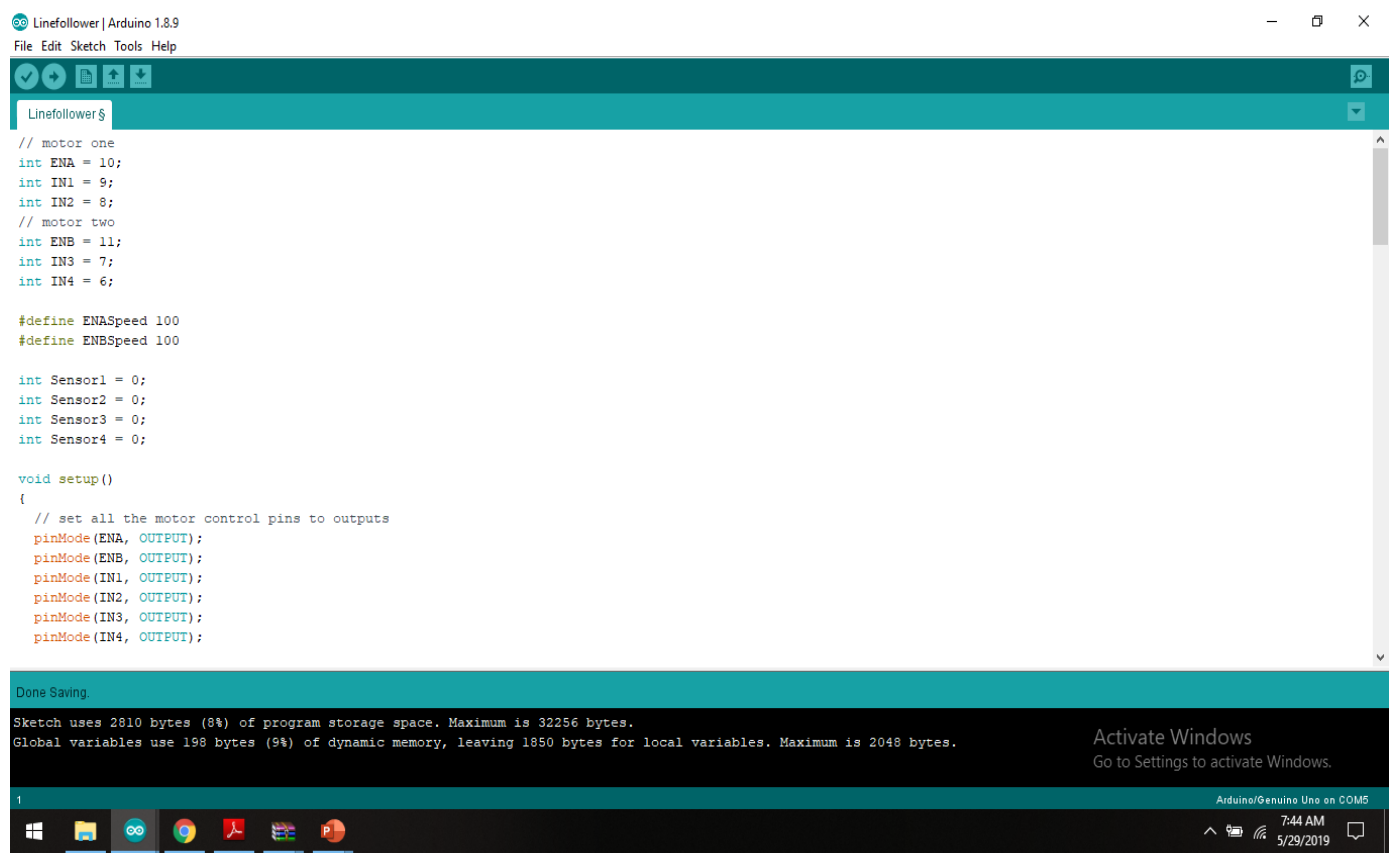

Gambar 11. Halaman kerja untuk memulai menuliskan program

\section{KESIMPULAN}

Terciptanya prototype robot cargo pengantar yang menggunakan arduino mega dan sensor ultrasonic. Dalam perancangan prototype robot cargo ini menggunakan bantuan motor DC, motor driver sebagai pengendali kecepatan. Beban yang dapat di tampung oleh prototype robot cargo ini kurang lebih $1 \mathrm{~s} / \mathrm{d} 2 \mathrm{Kg}$.

\section{REFERENCES}

[1] Kadir, Abdul, (2018), Dasar Pemograman Robot Menggunakan Arduino, Yogyakarta : Penerbit Andi.

[2] Purti, Andini dan Maspiyanti, Febri (2017), Robot Line Follower Pengantar Surat Menggunakan Metode Fuzzy Logic Studi Kasus Fakultas Teknik Universitas Pancasila, Jakarta : Jurnal Teknologi Terpadu Vol. 3, No.1.

[3] Falani, Achmad Z dan Budi, Setyawan, (2015), Robot Line Follower Berbasis Mikrokontroler Atmega 16 dengan Menampilkan Status Gerak Pada LCD, Surabaya : e-Jurnal NARADROID, Vol.1 No. 1.

[4] Adriansyah, Andi dan Hidayatama, Oka, (2013), Rancang Bangung Prototipe Elevator Menggunakan Microcontroller Arduino AT Mega 328P. Jakarta :Jurnal Teknologi Elektro, Vol.4 No.3.

[5] Yuliza dan Kholifah, Umi N, (2015), Robot Pembersih Lantai Berbasis Arduino Uno Dengan Sensor Ultrasonik, Jakarta Barat : Jurnal Teknologi Elektro, Vol.6 No.3.

[6] Lestari, Novi, (2017), Rancang Bangun Pintu Otomatis Menggunakan Arduino Uno dan PIR (Passive Infra Red) Sensor di SMP Negeri Simpang Semambang, Lubuklinggau : JUSIKOM, Vol 2 No.2.

[7] Aryani, Diah, et.al, (2013), Sistem Pengendalian Secara Otomatis Pada Robot Line Follower Menggunakan Mikrokontroler AT89S51, Tangerang : CSRID Journal, Vol.5 No.1.

[8] Birdayansyah, Radi, et al,(2015), Pengendalian Kecepatan Motor DC Menggunakan Perintah Suara Berbasis Mikrokontroler Arduino, Bandar Lampung : Jurnal Rekayasa dan Teknologi Elektro Volume 9, No.2.

[9] Dwiprasetiabudhi, Samuel F, et.al, (2015), Perancangan dan Realisasi Sistem Automatic Guided Vehicle (AGV) menggunakan Algoritma Dijkstra dan Fuzzy Logic, Bandung : e-Proceeding of Engineering : Vol.2,No.2.

[10] Wahyudi, Hebi J, et.al, (2015), Perancangan dan Realisasi Robot Line Follower untuk Pengangkut Sampah Otomatis, Bandung : e Proceeding of Applied Science : Vol 1, No.3. 